\title{
A indústria do resíduo: panorama das cooperativas de reciclagem e dos catadores de resíduos no estado do Rio de Janeiro
}

\author{
The waste industry: overview of cooperatives recycling and waste pickers in the \\ Rio de Janeiro State
}

\author{
Rafael Alves Esteves ${ }^{1}$
}

${ }^{1}$ Especialista em Gestão Ambiental e em Negócios Sustentáveis. Mestrando em Engenharia de Biossistemas - Escola de Engenharia, UFF, Niterói, RJ, Brasil

\begin{abstract}
RESUMO
A urbanização e o desenvolvimento da economia brasileira não tem sido suficientes para absorver e manter no mercado formal de trabalho uma parcela significativa da população. A crise social tem levado muitas pessoas a buscarem como forma de sobrevivência a catação de resíduos. Este trabalho busca traçar um panorama das cooperativas de reciclagem e dos catadores de resíduos à luz da sustentabilidade e do desenvolvimento sustentável. Subsidia uma reflexão sobre a importância destas organizações e de seus profissionais. A pesquisa mostra que a região Metropolitana é a que concentra maior número de cooperativas e de catadores no estado. No entanto, é a região Sul Fluminense em que os catadores conseguem maiores ganhos mensais. A maioria dos catadores são homens com idade de 25 a 45 anos e com o ensino fundamental incompleto. Reconhecem que contribuem para a problemática ambiental da sociedade e encontram na atividade de catar resíduos, uma forma de se reintegrarem na sociedade. Os resultados deste trabalho devem ser utilizados para desencadear reflexões, ampliar as discussões e mover ações de gestores públicos, visando melhorar as condições de trabalho destes profissionais, que são recursos humanos fundamentais para a gestão da sustentabilidade, minimizando os riscos à saúde e reduzir os prejuízos que os referidos materiais provocam para o meio ambiente.
\end{abstract}

Palavras-chave: Cooperativas de Reciclagem, Catadores de Resíduos, Desenvolvimento Sustentável, Gestão da Sustentabilidade

\begin{abstract}
The urbanization and the development of the Brazilian economy have not been sufficient to absorb and hold the formal labor market a significant portion of the population. The social crisis has led many people to seek in order to survive scavenging of waste. This paper has the objective to draw an overview of cooperatives recycling and waste pickers based in concepts of sustainability and sustainable development. It subsidizes a reflection on the importance of these organizations and their professionals. That research shows that the Metropolitan region is the one that focuses more cooperatives and collectors in the State. However, it is the South region where collectors get biggest monthly gains. Most collectors are men aged 25-45 years and with the elementary school. The professionals recognize that contribute to environmental problems of society and find the pick waste activity a way to reintegrate into society. These results should be used to stimulate reflections, broaden the discussion and move from public managers actions aimed at improving the working conditions of these professionals, who are key human resources for sustainability management, minimizing health risks and reduce losses causing said material to the environment.
\end{abstract}


Esteves, R.A.: A indústria do resíduo...

\section{Introdução}

O aumento do resíduo urbano e sua destinação é uma preocupação crescente na sociedade. Essa preocupação, aliada ao crescimento das consequências do impacto ambiental dos resíduos, tem estimulado o poder público e a sociedade a buscarem alternativas para a redução do impacto ambiental do resíduo urbano. Nesse sentido, verifica-se o desenvolvimento de programas e políticas públicas e de ações de organizações não governamentais, relacionados, principalmente, à coleta, separação e reciclagem desses resíduos (ZUCATTO et al. 2008).

Segundo Martins (2003), na perspectiva social, também se observa o crescimento de um grupo social de indivíduos considerados excluídos do mercado formal de trabalho e que tem encontrado no lixo uma alternativa de renda para sobrevivência. Diante disso, verifica-se, nos últimos anos, o surgimento de cooperativas populares de catadores e separadores de resíduos recicláveis, que possibilitam a geração de renda e a redução do impacto ambiental do resíduo urbano. Um fenômeno inicialmente limitado às grandes cidades, mas que tem se expandido por pequenos municípios brasileiros, os quais também enfrentam dificuldades com a destinação dos resíduos e a exclusão social.

É do conhecimento comum que as cooperativas de catadores de resíduo reciclável têm se mostrado excelente alternativa para o problema do volume excessivo de lixo gerado pelo consumismo da sociedade moderna. Estas cooperativas são organizadas para o desenvolvimento do trabalho de despoluição das cidades mediante a coleta seletiva de materiais recicláveis como alumínio, papelão, plástico, vidro, embalagens diversas, borracha, tecido, nylon e equipamentos eletrônicos.

Nesse sentido, é possível observar uma estreita relação entre os resíduos produzidos por uma população com a temática do Desenvolvimento Sustentável, uma vez que tal problemática recai exatamente sobre as principais dimensões que propiciam a Gestão da Sustentabilidade: sociais, econômicas e ambientais, conforme são descritos as relações a seguir.

Para Neto et al. (2007) existe uma relação com equidade social pelo fato de muitas pessoas sobreviverem do "reaproveitamento" do resíduo produzido nas cidades, problema que também possui ligação com a questão econômica já que a reciclagem desses resíduos será uma fonte de renda para o catador/cooperado; e por fim, o equilíbrio ambiental, pelo fato da minimização dos resíduos em locais inadequados que causam fortes impactos no ambiente, ocasionando o desequilíbrio ambiental vivenciado atualmente. Portanto, o tratamento correto dos resíduos sólidos em uma localidade, contribuirá positivamente para a sustentabilidade da mesma de modo a diminuir significativamente os problemas ambientais decorrentes do acúmulo dos resíduos sólidos urbanos.

\subsection{Situação-Problema}

Como forma de contribuir para o alcance do desenvolvimento sustentável, destaca-se o papel das cooperativas de catadores de resíduos recicláveis que funcionam como um mecanismo de auxílio à redução dos efeitos maléficos causados pelo acúmulo de resíduos sólidos nos lixões em meio urbano.

Segundo Chikarmane (2009), os catadores de resíduos recicláveis desempenham um papel significativo nos países em desenvolvimento. Dentre os benefícios que resultam da coleta, separação e reciclagem dos resíduos, além da geração de renda e inclusão social dos trabalhadores envolvidos, pode-se citar: a contribuição à saúde publica e ao sistema de saneamento; o fornecimento de material reciclável de baixo custo à industria; a redução nos gastos municipais e a contribuição à sustentabilidade do meio ambiente, tanto pela diminuição da matéria-prima primária utilizada, que conserva recursos e energia, tanto pela diminuição da necessidade de terrenos a serem utilizados como lixões e aterros sanitários. 
Diante desse contexto, configura-se a situação-problema da pesquisa: se o papel das cooperativas de reciclagem é, de fato, importante para a sociedade, quais são as condições ambientais, de vida e de trabalho dos catadores cooperados? Já que os catadores de resíduos atuam como um dos principais atores envolvidos na gestão da sustentabilidade nas cidades brasileiras, por que, então, seu trabalho não tem o devido valor na sociedade? Será que a gestão da sustentabilidade, no que tange as atividades das cooperativas de reciclagem, é insustentável quando analisados o perfil dos catadores que constituem estas cooperativas? É norteado por essas questões que foi desenvolvido este trabalho de pesquisa.

\subsection{Objetivos}

A partir da definição da situação-problema apresentada acima, o objetivo geral deste trabalho é traçar um panorama atualizado das cooperativas de reciclagem e dos catadores de material reciclável em todo o estado do Rio de Janeiro, com foco nas condições de vida e de trabalho destes cooperados.

Para atingir o objetivo geral, os objetivos específicos são: i) mapear as cooperativas de resíduos existentes nos 92 municípios que compõem o estado do Rio de Janeiro; ii) identificar as especificidades de cada cooperativa; iii) estudar, preliminarmente, à luz da sustentabilidade e do desenvolvimento sustentável, o perfil das cooperativas e de seus catadores/cooperados.

\subsection{Estrutura do Trabalho}

Em termos metodológicos, trata-se de uma pesquisa exploratória, descritiva de abordagem quantitativa, conduzida sob a forma de um estudo com escopo de abrangência delimitado nos municípios de todo o estado do Rio de Janeiro.

Este trabalho está organizado em cinco seções. Além da presente introdução, identifica-se na segunda seção um levantamento teórico capaz de subsidiar a pesquisa, ao longo de seu desenvolvimento. Na seção três são apresentados os aspectos metodológicos e a forma como este estudo foi conduzido. A seguir são apresentados os dados obtidos com a pesquisa e é realizada a análise dos resultados alcançados. Por fim, segue as considerações finais e conclusões do trabalho.

\section{Referencial Teórico}

\subsection{Desenvolvimento Sustentável}

Para Santos et al. (2001), durante muitos anos a sociedade utilizava um modelo de desenvolvimento baseado apenas na elevação dos índices econômicos, considerando que as fontes de matérias-primas seriam inesgotáveis e que o planeta assimilaria os resíduos indefinidamente, além de que a geração de poluentes seria inevitável na produção de bens e serviços e que a tecnologia seria capaz de resolver todos os problemas surgidos da aplicação desse modelo.

No entanto, ainda em consonância com Santos et al., no início da década de 1970, como uma resposta à preocupação da humanidade, diante da crise ambiental e social que se abateu sobre o mundo desde a segunda metade do século passado, foi possível perceber que o planeta não seria capaz de absorver todo o rejeito oriundo das atividades do homem, nem as tecnologias, apesar de suas inovações plausíveis, solucionariam todos os problemas, visto que o planeta é um sistema fechado, limitado e esgotável, não podendo sustentar indefinidamente o crescimento da sociedade humana consumindo bens e serviços infinitamente.

Diante da problemática Santos et al. (2001), avança na sua exposição e afirma que surge a busca pelo novo paradigma de desenvolvimento e que este seja sustentável, buscando conciliar o desenvolvimento econômico com a preservação ambiental e, ainda, manter boas relações sociais, ou seja, desenvolver em harmonia com as limitações ecológicas do planeta para que as gerações futuras tenham a chance de existir e viver bem, de acordo com as suas próprias necessidades. 
O entendimento de um tema tão complexo e de numerosos conceitos, como o desenvolvimento sustentável, requer uma mudança de valores, ideologias, princípios ético, além de um novo repensar acerca da amplitude de fatores que abrangem tal desenvolvimento. Com esta complexidade, é possível criar um delimitador da temática, o conceito da Gestão da Sustentabilidade, que, supõe-se, seja a capacidade de gerir o tema do desenvolvimento sustentável com a visão estratégica de crescimento das suas dimensões básicas.

Segundo Barreto (2004), a ideia de sustentável indica algo capaz de ser suportável, duradouro e conservável, apresentando uma imagem de continuidade. Trata-se da emergência de um novo paradigma para orientação dos processos, de uma reavaliação dos relacionamentos da economia e da sociedade com a natureza e do Estado com a sociedade civil.

Entender a complexidade que o tema apresenta é de suma importância, assim sendo, se faz necessário abordar conceitos sobre o que vem a ser desenvolvimento sustentável. A definição do desenvolvimento sustentável pode ser compreendida como aquela que atende às necessidades do presente sem comprometer a possibilidade de as gerações futuras atenderem as suas próprias necessidades.

\begin{abstract}
"Desenvolvimento sustentável é aquele que atende às necessidades do presente sem comprometer a possibilidade de as gerações futuras atenderem às suas próprias necessidades, ou ainda, desenvolvimento sustentável não é um estado fixo de harmonia, mas um processo de mudanças na qual a exploração de recursos, a direção dos investimentos, a orientação do desenvolvimento tecnológico $e$ as mudanças institucionais serão feitas consistentemente ao atendimento às necessidades do presente sem comprometer a possibilidade de as gerações futuras atenderem as suas próprias necessidades".
\end{abstract}

(Our Commom Future, 1987)

Conforme mencionado por Baquero e Cremonese (2006), uma das características essenciais do desenvolvimento sustentável, ao contrário da forma tradicional de desenvolvimento, diz respeito não apenas a proteção do meio ambiente, mas incorporam, sobretudo, as pessoas, suas necessidades e como elas podem ser satisfeitas equitativamente no contexto atual.

É relevante destacar que esse conceito de desenvolvimento sustentável é de fácil aceitação e apresenta-se muito eficiente em termo teórico. Porém, de acordo com Franco (2000), sua formulação parte de uma concepção sistêmica, abrangendo questões ambientais, tecnológicas, econômica, cultural e política, sendo assim, apresenta grande complexidade em sua aplicação, haja vista que, fatores como a pobreza, poluição, tecnologia e formas de vida estão presentes e exigem mudanças de comportamentos na forma de agir, pensar, produzir e de consumir da humanidade, bem como, a participação de todos os segmentos da sociedade para a implementação dessas mudanças.

Para sintetizar, pode-se afirmar que desenvolvimento sustentável assemelha-se ao atendimento das necessidades e carências das gerações atuais sem prejudicar a capacidade das gerações futuras conseguirem suprir com suas próprias necessidades e carências. Entretanto, observase a partir desta conceituação, que há muitos desafios a serem vencidos, quer seja dos poderes públicos, ou da própria sociedade, a fim de se alcançar a sustentabilidade das relações homem em contraponto com o meio ambiente.

Apesar de disseminado entre as diversas esferas da sociedade o conceito de desenvolvimento sustentável, necessita de uma clara delimitação do que se pretendem sustentar e quem tem a responsabilidade sobre essa nova denominação de desenvolvimento, fazendo-se necessária melhor exploração da temática pertinente à gestão da sustentabilidade.

\title{
2.2 A Importância das Cooperativas de Reciclagem
}

As cooperativas de catadores de material reciclável constituem uma eficiente alternativa para a destinação do volume excessivo de lixo assim como para um maior equilíbrio na distribuição de rendas nas sociedades. 
Segundo Teixeira e Malheiros (2010), o cooperativismo é dotado de princípios de elevada nobreza e valor humano, os quais são capazes de criar uma dimensão superior de administração das atividades econômicas governamentais, e empresariais, com o firme propósito de consolidar benefícios sociais, e autônomos, aos participantes dos atos cooperados e suas relações técnicas e comerciais, sem fins lucrativos e praticamente isentos de impostos.

O Brasil, apesar de ser uma das maiores economias do mundo (FUNAG, 2015), possui uma das piores distribuições de renda no mundo (OCDE, 2013), fato que tem levado milhares de pessoas a buscarem a sobrevivência nas ruas através da coleta de materiais recicláveis. Para Silva et al. (20019), tal atividade, além da exposição dos catadores aos riscos de acidentes, é vista negativamente pela sociedade, em geral, por ser realizada de forma desorganizada, utilizando-se as ruas e terrenos baldios para segregar e armazenar o material recolhido, dificultando o trabalho do serviço público de limpeza. Por outro lado, Lima e Cordeiro (2013), afirma que ao se organizarem através de cooperativas ou associações de catadores, tais trabalhadores podem se tornar parceiros de programas institucionais de coleta seletiva e mudar este perfil estigmatizado.

$\mathrm{Na}$ amplitude do surgimento das cooperativas e o acompanhamento de sua gestão por parte da iniciativa pública e privada em seus métodos, podemos observar que o trabalho destas organizações possibilita os seguintes benefícios aos atores envolvidos com a gestão da sustentabilidade:

- A geração de emprego e renda;

- Resgate da cidadania dos catadores/cooperados;

- Retirada de catadores das ruas, dos lixões e de diversas situações insalubres;

- Organização do trabalho dos catadores nas ruas evitando os problemas na coleta do resíduo e o armazenamento de materiais recicláveis em logradouros públicos;

- Redução das despesas com programas de coleta seletiva nas instituições, públicas e privadas;

- Redução das despesas com coleta, transferência e disposição final de resíduos separados pelos catadores e que não serão encaminhados ao local de disposição final;

- Contribuição à saúde publica e ao sistema de saneamento;

- Fornecimento de material reciclável de baixo custo à indústria;

- Redução nos gastos municipais e a contribuição à sustentabilidade do meio ambiente, tanto pela diminuição da matéria-prima utilizada, que conserva recursos e energia, tanto pela diminuição da necessidade de terrenos a serem utilizados como lixões e aterros sanitários.

Observa-se que os catadores de resíduos recicláveis cooperativados, assim como outros cooperados, trabalham em prol dos mesmos ideais e unidos pelos mesmos objetivos. Assim direcionam as suas atividades para a satisfação das suas necessidades financeiras e pessoais através da produtividade e da valorização do trabalho e não da exploração da força de trabalho.

Como negócio comercial, as cooperativas atuam na coleta, separação e venda do material reciclável recolhido para os consumidores de material selecionado. Este negócio bem gerido permite a negociação de um preço mais justo e também que grandes compradores como fábricas tenham fácil acesso a estes materiais, o que possibilita que possam o utilizar como matéria-prima para seus produtos de maneira rentável e ainda, agregar aos seus produtos o valor social.

\subsection{Os Catadores de Resíduos - Percepções Gerais}

Segundo Fraga (2012), muitos homens e mulheres, excluídos de formas "reconhecidas de trabalho", encontram na atividade de coletar e vender resíduos a forma de terem a identidade de trabalhadores recuperada. É a partir das sobras, do resto, que eles voltam a prover financeiramente a si mesmos e as suas famílias. O catador vai contra a lógica predominante na sociedade, de que o que é descartado, aquilo que é rejeitado e tem que ser jogado fora, para ele representa algo que ainda pode ser aproveitado, seu meio de vida.

Os catadores buscam uma forma de inserção no mundo social e do trabalho, realizando uma atividade relevante para a sociedade, o meio ambiente e, $\mathrm{m}$ uma visão macro do processo, para a 
gestão da sustentabilidade. Em um levantamento superficial realizado por Medeiros e Macedo (2006), os catadores de materiais recicláveis configuram-se como sendo trabalhadores de um grupo de desempregados, que, por sua idade, condição social e baixa escolaridade, não encontram lugar no mercado formal de trabalho.

Segundo Abreu (2011), o catador de material reciclável é uma modernização da figura do "velho garrafeiro" ou, ainda "o homem do saco" do início do século XX. Atualmente, os catadores de material reciclável são trabalhadores informais que coletam grande quantidade de materiais recicláveis nos centros urbanos e revendem a intermediários.

Os catadores de resíduos são os principais agentes da coleta seletiva em muitas cidades do País. Às vezes eles movimentam mais recursos financeiros com a reciclagem que as próprias prefeituras, empresas e cooperativas. Muitos deles são pais de família e responsáveis pelo sustento da casa, chegando a ganhar acima do valor mínimo do salário vigente.

Como percepções gerais, os catadores estão construindo sua história e conquistando o seu reconhecimento como categoria profissional, oficializada na Classificação de Ocupações Brasileiras (CBO), no ano de 2002. Nessa classificação, os catadores de material reciclável são registrados sob o número 5192-05 e sua ocupação descrita como "catador de material reciclável". Segundo a descrição sumária de suas atividades na $\mathrm{CBO}$, os catadores "coletam, selecionam e vendem materiais recicláveis como, por exemplo, papel, papelão, plástico, vidro, bem como materiais ferrosos e não ferrosos, e ainda, materiais reaproveitáveis".

\section{Metodologia}

O presente trabalho de pesquisa caracteriza-se como exploratória, por proporcionar, segundo Gil (1998), "maior familiaridade com o problema, com vistas a torná-los mais explícito", e descritiva por apresentar a descrição das características de dada população ou fenômeno em estudo. A abordagem é do tipo quantitativa, pois utilizou instrumentos estruturados para o alcance da percepção e análise detalhada do objeto em estudo (Cavalcante e Dantas, 2006). Foi conduzido sob a forma de um estudo com o escopo de abrangência delimitado no estado do Rio de Janeiro, onde se buscou contemplar todos os municípios que compõe do estado.

Inicialmente foi realizada uma pesquisa de mapeamento em banco de dados de instituições publicas e privadas especializadas no tema de promoção da reciclagem no Brasil, de modo que fornecessem dados suficientes para que os 92 municípios do estado do Rio de Janeiro pudessem ser contemplados neste estudo e que fosse representativo para traçar o panorama das organizações e seus cooperados. A pesquisa foi realizada no período compreendido entre novembro de 2012 a junho de 2013 e contou com o levantamento de dados disponíveis nas prefeituras das cidades do Estado do Rio de Janeiro, consulta a literatura encontrada nas bibliotecas das universidades UERJ, UFRJ, UFF, UNIRIO, UFRRJ, USS, INIFOA, UNIFESO, Estacio de Sá e Unigranrio, como fontes de produção de materiais locais. Ainda foram utilizados bancos de dados de instituições sem fins lucrativos que militam na temática sustentável, como CBEDS e CEMPRE.

Como premissa, somente foram objetos de análise organizações legalmente estabelecidos e catadores formalmente cooperados, detentores de direitos e deveres perante tais organizações. Todos os 92 municípios do estado do Rio de Janeiro tiverem amostras representativas analisadas, que, dependente das variáveis de tamanho, densidade populacional e estrutura comercial do município, os grupos analisados não, necessariamente, configuram-se cooperativas e sim associações ou grupos organizados de catadores de materiais recicláveis.

Em seguida, por meio de visitas in loco e de contato telefônico, através de entrevistas com os profissionais coletores de resíduos, foram levantadas as especificidades de cada cooperativa e das organizações inerentes aos cooperados. Foram identificadas também as particularidades, condições ambientais de trabalho e vida dos trabalhadores.

O trabalho de coleta dos dados e identificação das particularidades de cada grupo amostral foi realizado no período entre junho de 2013 e janeiro de 2014. Os levantamentos foram realizados com base em um questionário montado para aplicação aos participantes. No entanto, devido a limitações 
de tempo e de conhecimento de escrita e leitura de alguns participantes, o questionário foi aplicado em forma de conversa informal, sendo extraídas e compiladas todas as informações necessárias para a obtenção dos resultados no momento do diálogo.

O questionário balizador da entrevista/conversa informal com os participantes contemplou questões que buscavam conhecimento sobre as especificidades econômicas, sociais e ambientais, tanto das cooperativas enquanto organizações, como do catador/cooperado.

A análise e tratamento dos dados foram apoiados quantitativamente e apresentados através de linguagem discursiva. Quanto ao tratamento, aplicou-se o método de análise por conteúdo, comparando os dados obtidos na etapa da coleta de dados e identificação das particularidades de cada grupo amostral à luz dos preceitos da sustentabilidade e do desenvolvimento sustentável.

\section{Resultados e Discussões}

O estado do Rio de Janeiro chegou em 2010 com uma população de 15.989.929 habitantes, segundo dados do Instituto Brasileiro de Geografia e Estatística - IBGE (2010). Durante os anos 2000 experimentou um incremento populacional da ordem de 1,5 milhões de pessoas aproximadamente. Apesar de algumas mudanças, o peso da população metropolitana no estado permanece bastante elevado, 75,7\% em 2000 e 74,2\% em 2010, ainda de acordo com dados do IBGE.

A divisão do território estadual apresenta sete mesorregiões geográficas: Baixadas Litorâneas, Centro Fluminense, Metropolitana, Noroeste Fluminense, Norte Fluminense, Sul Fluminense e Região Serrana. No contexto do desenvolvimento do estado do Rio de Janeiro concentram-se, em torno da capital, vários municípios que crescem e dependem da metrópole, uma vez que estavam integrados a ela. Esta região Metropolitana em muito se diferencia das outras regiões do estado, inclusive em termos da existência e organização das atividades de cooperativas e catadores de materiais recicláveis.

Foi analisado o total de 408 cooperativas de reciclagem em todo o estado do Rio de Janeiro. Deste total, somam 6502 catadores cooperados em atividade hoje no estado. A maior concentração de cooperativas e, consequentemente, com maior número de catadores, encontra-se na região Metropolitana do estado, com o total na região de 226 cooperativas, mais especificamente na capital, município do Rio de Janeiro, presente com 113 cooperativas analisadas que somam 902 catadores cooperados. Em contrapartida, a região que menos dispõe de organizações cooperativas é a Noroeste Fluminense, com 14 cooperativas instaladas na região. No entanto, o município que dispõe de menor número de cooperativas e de catadores é Quatis, município localizado na região Sul Fluminense, que conta apenas com uma cooperativa e três catadores.

Segue abaixo a Figura 1 com a distribuição das cooperativas e dos catadores por região no estado do Rio de Janeiro.

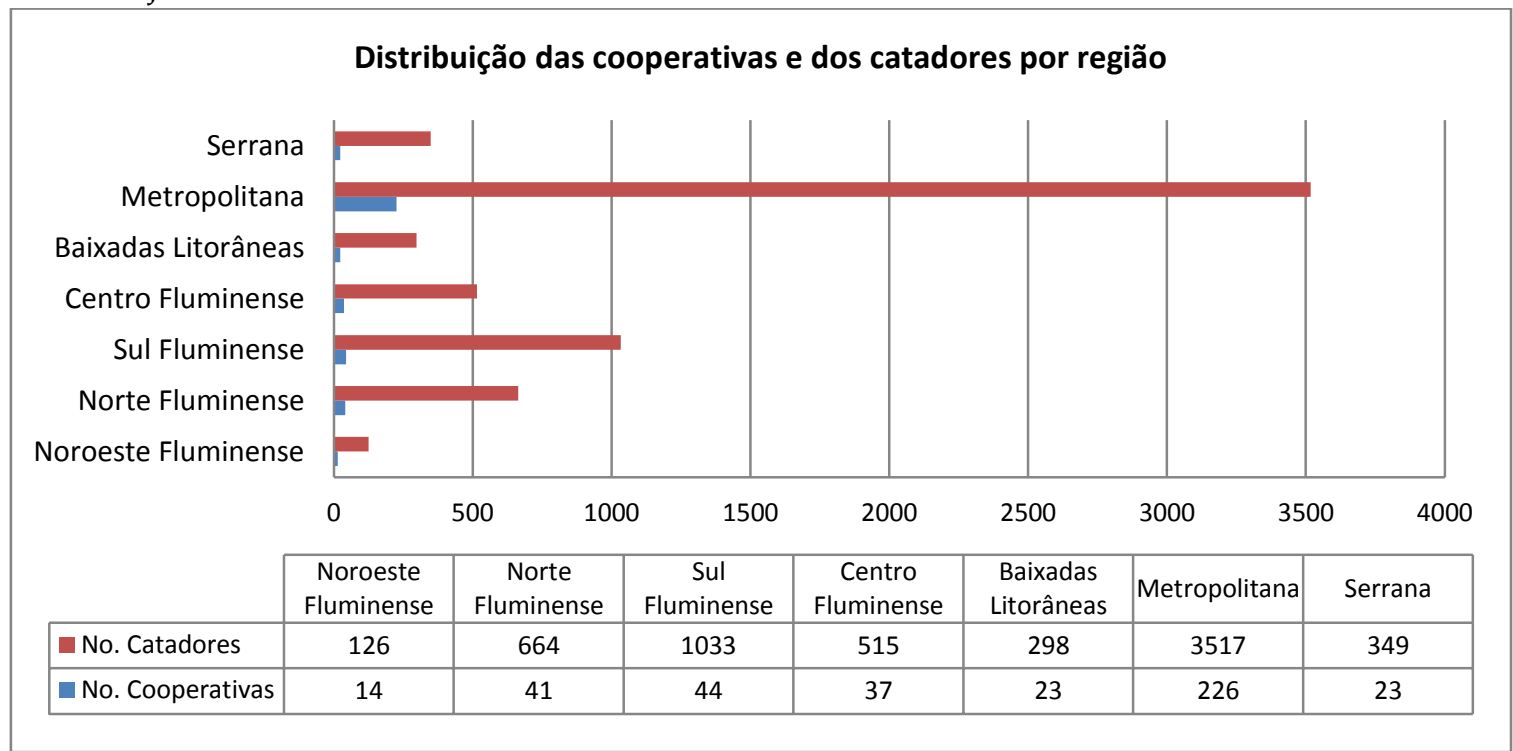

Figura 1. Distribuição das cooperativas de reciclagem e dos catadores de materiais recicláveis por região no estado do Rio de Janeiro. Fonte: Baseado na pesquisa de campo. 


\subsection{Perfil das Cooperativas}

O perfil das cooperativas de reciclagem traçado por este estudo buscou compreender o modo como estas organizações se comportam nas dimensões econômica, ambiental e social frente aos seus catadores/cooperados e frente à localidade onde estão inseridas.

Como já citado acima, o negócio básico de toda cooperativa de reciclagem se compreende nas etapas de coleta do material reciclável, separação deste material e a posterior venda destes materiais para indústrias que os utilizam em seus processos produtivos. Os resultados obtidos mostram que, dentre os materiais mais comuns inseridos no processo da reciclagem, o alumínio, plástico (principalmente embalagens tipo pet) e o papel são os materiais mais trabalhados nas cooperativas (todas as cooperativas estudadas trabalham estes materiais). Em contrapartida, os resultados mostram que poucas cooperativas no estado trabalham a reciclagem das embalagens longa vida. No entanto, é possível concluir que, a reciclagem de equipamentos eletrônicos ainda é extremamente restrita hoje no estado, havendo somente seis cooperativas que coletam este tipo de material na região Metropolitana, uma na região Sul Fluminense e uma na região Norte Fluminense, totalizando oito em todo o estado, como ilustra a Figura 2 abaixo:

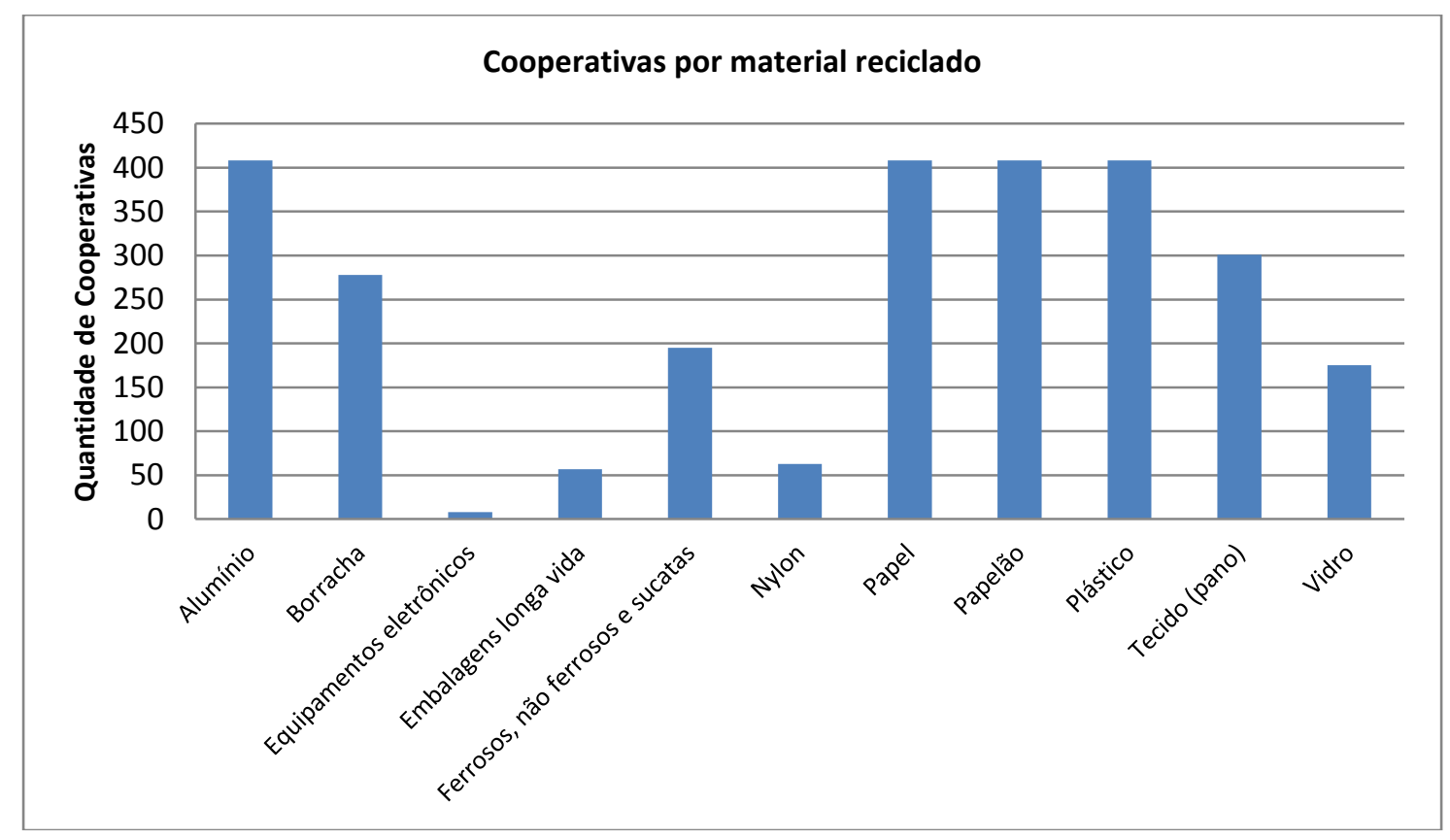

Figura 2. Quantidade de cooperativas por tipologia de material reciclado/trabalhado. Fonte: Baseado na pesquisa de campo.

Com relação à movimentação econômica das cooperativas no estado, os resultados apontam diferença de até $15,1 \%$ de diferença entre a região de maior faturamento (região Metropolitana) quando comparado com a de menor faturamento (região Noroeste Fluminense). Os faturamentos médios mensal das organizações nas regiões estão assim distribuídos: Noroeste Fluminense, R $\$ 8.000$; Norte Fluminense, R $\$ 35.520,00$; Sul Fluminense, $\mathrm{R} \$ 41.566,00$; Centro Fluminense, $\mathrm{R} \$ 23.890,00$; Baixadas Litorâneas, $\mathrm{R} \$ 20.050,00$; Serrana, $\mathrm{R} \$ 32.000,00$ e Metropolitana, $\mathrm{R} \$ 53.000,00$.

A divisão do lucro em $79 \%$ das cooperativas analisadas é feita com base no total de ganhos no mês, subtraído pelas despesas no mesmo período e dividida igualmente a todos da organização. 13\% das cooperativas aplicam o mesmo método de divisão, porém, os cooperados são obrigados a contribuir com uma quantia para um "fundo de necessidades". As cooperativas que totalizam os $8 \%$ restante fogem da normalidade de regimento de uma "cooperativa", diferenciando as remunerações de acordo com a atividade exercida. Nestas, há profissionais que trabalham na parte administrativa que ganham mais do que os catadores ou separadores. 
$\mathrm{Na}$ investigação das condições de trabalho submetidas aos catadores/cooperados, $73 \%$ de todas as cooperativas estudadas fornecem equipamentos de proteção individual (luvas, óculos, jaleco, máscaras e botas) aos profissionais. Das 408 cooperativas analisadas, foi verificado in loco aproximadamente 215. Considerando as condições encontradas das cooperativas que foram possíveis a análise no local, 13\% delas não apresentaram ambientes limpos e organizados em condições salubres de trabalho.

Ao analisar a relação das cooperativas com as comunidades ao entorno das organizações, pode-se ter uma percepção amigável e de satisfação pelo e reconhecimento do trabalho realizado por elas. Não foi evidenciado registro de reclamações ou descontentamento da sociedade frente ao trabalho desempenhado pelas cooperativas, em nenhum aspecto.

\subsection{Perfil dos Catadores}

Foram analisados os dados sociodemográficos dos participantes da pesquisa, com o objetivo de estabelecer relações quanto ao gênero, escolaridade, estado civil, idade, filhos, situação econômica, dentre outros.

Dos catadores entrevistados, $69 \%$ são do sexo masculino, configurando a maioria entre os profissionais. A predominância masculina é entendida ainda como um fator histórico, dada as condições em que o catador é submetido em termos de esforço braçal. Mais de $70 \%$ da atividade do catador é realizado através de um "carrinho" que ele carrega utilizando a sua própria força e que pode chegar a mais de $200 \mathrm{~kg}$ por dia, transportado por longas distâncias nas mais variadas condições climáticas.

No que se refere à escolaridade, $9 \%$ são analfabetos e $77 \%$ tem apenas o ensino fundamental incompleto e $14 \%$ possui o ensino médio incompleto. No entanto, em muitos casos, observa-se o interesse em continuar os estudos, principalmente nas mulheres mais jovens. Em um comparativo, a baixa escolaridade igualmente foi observada em trabalhos anteriores, realizadas por Silva (2002), Magera (2003), Martins (2007) e Bosi (2008), em várias regiões do país. Segundo esses autores, o grau de escolaridade é um dos motivos que leva as pessoas à exclusão do mercado formal de trabalho.

Quanto ao estado civil, 55\% dos catadores são solteiros, 36\% deles são casados (ou em estado de concubinato) e $44 \%$ possuem filhos. Em estudo realizado em Goiânia, GO, foi observado que dos entrevistados que não moram sozinhos, $44 \%$ são responsáveis pela renda da família (Ferreira et al, 2006, citado por Kircheneret AL, 2009).

Em relação à distribuição por faixa etária, grande parte dos catadores, 56,5\% possui idade entre 25 a 45 anos e 39,5\% de 45 a 65 anos. Em pesquisa realizada por Bosi (2008) o fator idade revela uma predominância de sujeitos entre 30 e 60 anos. A população de catadores é formada basicamente por adultos jovens, embora ocorra uma grande elasticidade na distribuição da mesma (Porto et al, 2004). Na atual conjuntura econômica do Brasil, a idade é um dos fatores que afetam predominantemente a forma de participação no mercado de trabalho formal, sendo que este é mais favorável na admissão de jovens. Isto não ocorre na catação, pois não existem critérios de seleção para realizar esta atividade.

Referente ao retorno financeiro dos catadores analisados, mais da metade, 58\% deles considera suficiente o valor conseguido pelo trabalho. Este resultado reflete a realidade do estado como um todo, porém há diferenças nos valores médios alcançados pelos catadores quando comparado as diferentes regiões do estado, como mostra a Figura 3 abaixo: 


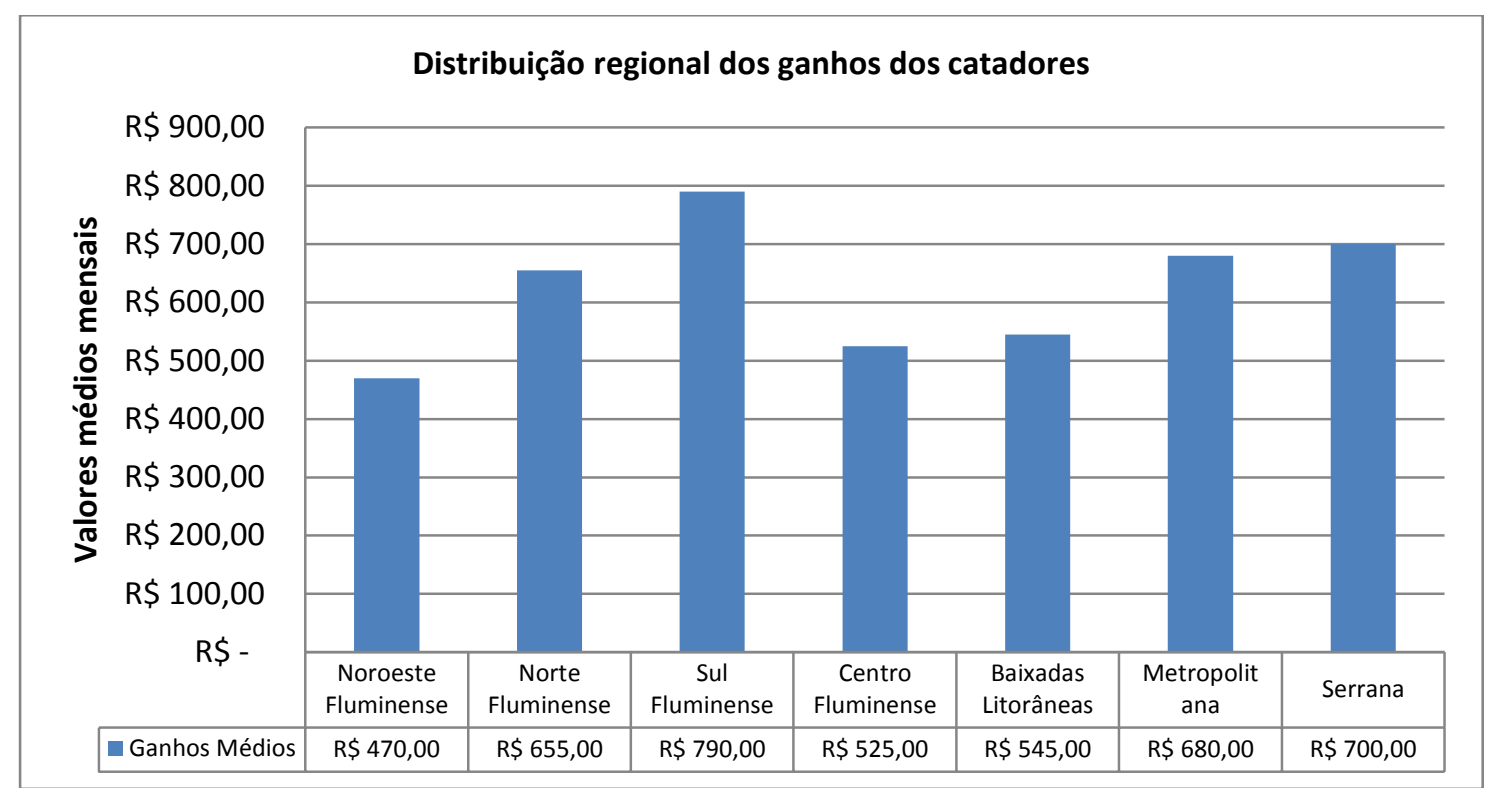

Figura 3. Distribuição regional dos valores médios mensais conseguidos pelos catadores. Fonte: Baseado na pesquisa de campo.

Do total, aproximadamente $60 \%$ dos catadores conseguem menos de um salário mínimo ao mês. Contudo, mesmo com os valores apresentados, $51 \%$ dos entrevistados possuem casa própria ou não pagam aluguel para moradia. Se analisarmos apenas a região Metropolitana do Rio de Janeiro, observa-se que $71 \%$ dos entrevistados possuem casas próprias ou não pagam aluguem para moradia. Os dados obtidos correspondem com outro estudo realizado por Porto et al (2004), quando o autor fez um estudo de caso com catadores de um aterro metropolitano no Rio de Janeiro e verificou que na maioria dos casos, os catadores residiam em casas próprias (79\%).

Em relação à realidade de trabalho a qual os catadores são submetidos, $27,8 \%$ deles afirmam que já sofreram algum tipo de acidente de trabalho, principalmente por corte e perfuração de pele devido ao mau acondicionamento dos resíduos coletados. Um dado que contrasta com o resultado obtido no perfil das cooperativas é que $44 \%$ dos entrevistados alegam não trabalhar fazendo uso dos equipamentos de proteção individuais apropriados ao tipo de trabalho realizado, nem que os mesmos são disponibilizados pelas cooperativas.

Foi estudada a relação entre os dados sociodemográficos e o principal fator que levou o entrevistado a atuar como catador. Segundo resultados obtidos, a maioria entre as mulheres (31\%) são catadoras por "necessidade", totalizando 20,8\%, entretanto para os homens entrevistados (69\%), atuar como catador foi considerada a "única oportunidade", somando 29,2\%. Para Ferreira (2005, citado em Kircheneret al, 2009), em Uberlândia as necessidades básicas foi considerada o motivo principal que levou $90 \%$ das pessoas (entre homens e mulheres) a realizar a coleta de lixo. Quanto à relação com estado civil pode ser observada que entre os solteiros $(55 \%)$ quase a metade $(24,0 \%)$ considera a variável "necessidade" e entre os casados (36\%) é considerada a "única oportunidade" (16,7\%) como principal fator da sua atuação como catador. Em relação ao principal fator e a distribuição por faixa etária, para os catadores entre 25 a 45 anos (56,5\%) foram considerados a "única oportunidade" e entre os mais velhos (45 a 65 anos) foram identificados como "necessidade" a atuação como catador.

Os entrevistados consideram como principais motivos que os levaram a trabalhar como catadores foi a "necessidade" e esta atividade a "única oportunidade". Segundo Medeiros e Macedo (2007) o trabalho ocupa um lugar central na vida de quem o realiza, sendo ele um meio de subsistência e de integração social, pois possibilita o relacionamento entre pessoas, a inclusão social e o sentimento de pertencer a um grupo. Conforme Miura (2004), parte dos trabalhadores da catação é oriundo da população desempregada, que atingidos por idade, condição social e baixa escolaridade, não encontram espaço no mercado formal de trabalho. Um estudo feito por Ferreira na cidade de Uberlândia (2005), o principal motivo identificador entre os catadores entrevistados foi a sobrevivência. 
Para os catadores analisados, a percepção de boa aceitabilidade de suas atividades junto às comunidades onde estão inseridos é real e satisfatória. No trabalho realizado por Miura (2004), atualmente o problema está em reconhecer o direito do catador às condições dignas de trabalho e de vida, que vá para além da sobrevivência. Em outro estudo realizado por Meirelles (2008), os catadores de materiais recicláveis desenvolvem uma atividade socialmente rejeitada, sendo essa um exemplo do processo de exclusão social.

Foram avaliadas, também, as percepções dos catadores quanto às suas contribuições para a sociedade e para o meio ambiente. Importante observar que, além da necessidade financeira em prover sustento a si mesmo e para a família, os catadores acreditam que suas atividades são de grande importância ao meio ambiente e a sociedade. A maioria, aproximadamente 33,7\% dos entrevistados, se sente motivados a trabalhar quando pensam nos benefício que seus trabalhos acarretam principalmente no que tange a "limpeza das cidades", e, cerca de 30\%, para o "controle e despoluição dos rios". Este último, motivo de grande preocupação em algumas regiões do estado do Rio de Janeiro, principalmente as Serrana, Metropolitana e Centro Fluminense que são, constantemente, foco de enchentes e desmoronamentos de terras devido a alagamentos e falta de escoação natural das águas pluviais.

Em uma discussão iniciada por Rosado (2007, p.7), “os catadores, conscientes ou não, tem papel fundamental na reinserção de materiais pós-consumo à cadeia de produção, realimentando-a, mas também contribuindo para a economia de energia e evitando a extração de bens naturais, sabidamente cada vez mais caros". Para Medeiros e Macedo (2006) a contribuição dessa classe de trabalhadores é inquestionável sob o aspecto ambiental e, para, além disso, o fruto de seu trabalho é ponto de partida para o abastecimento, com matérias-primas, das indústrias de reciclagem.

Os resultados mostram que $75 \%$ dos entrevistados trocariam de trabalho se tivessem outra oportunidade e o mesmo percentual sofre discriminação por causa do trabalho. Para os catadores, eles sofrem com a humilhação, preconceito e desprezo dos moradores. Os resultados também apontam que $37 \%$ dos catadores não se encontram satisfeitos com a situação atual que vivem, isso em todas as regiões do estado. Outra pesquisa realizada no Rio de Janeiro, por Porto et al (2004) os catadores enfrentam dificuldades no dia-a-dia e tem sonhos, como ter uma casa melhor e conseguir um emprego de carteira assinada.

\section{Conclusão}

O objetivo geral desse estudo foi alcançado, possibilitando compreender e traçar um perfil das cooperativas de reciclagem e dos catadores de resíduo reciclável no estado do Rio de Janeiro.

Os resultados mostram que ainda é tímida a reciclagem de materiais como embalagens longa vida, que apresentaram apenas 57 cooperativas em todo o estado. Situação pior ainda quando analisadas as cooperativas que reciclam equipamentos eletrônicos, apenas oito, sendo seis na região Metropolitana do estado. Seguindo a tendência nacional, conclui-se que no Rio de Janeiro os materiais mais reciclados em todas as regiões do estado são o alumínio, o plástico (principalmente o pet) e o papel.

A região que mais possui cooperativa e, consequentemente, catadores é a Metropolitana, contando com o total de 226 cooperativas e, aproximadamente, 3517 catadores. Esta região contrasta diretamente com a região Noroeste Fluminense, região que possui menor número de cooperativas e de catadores do estado, com apenas 14 organizações e 126 profissionais. Com relação ao faturamento médio mensal das cooperativas, a região Metropolitana apresenta os maiores ganhos obtida pelas organizações, girando em torno de $\mathrm{R} \$ 53.000,00$ por mês. Contrasta ainda com os dados da região com menor número de cooperativas e catadores, Noroeste Fluminense, onde o faturamento médio mensal gira em torno de $\mathrm{R} \$ 8.000,00$. A diferença de faturamento entre estas duas regiões é de 15,1\%.

Em relação ao perfil dos catadores, os resultados mostram que a maioria é constituída por homens (69\%) adultos com idade compreendida entre 25 e 45 anos (56,5\%). Do total de entrevistados, 9\% são analfabetos, $77 \%$ possuem ensino fundamental incompleto e $14 \%$ possuem o ensino médio incompleto (ou estão em curso). Como percepção, observa-se maior interesse em dar continuidade nos 
estudos as mulheres jovens, com a alegação de conseguirem "uma coisa melhor e com carteira assinada". $55 \%$ de todos os entrevistados são solteiros e $44 \%$ possuem filho(s).

Os catadores conseguem maiores ganhos em suas atividades nas regiões Sul Fluminense (com rendimento médio mensal de $R \$ 790,00)$ e na Serrana $(R \$ 700,00)$, seguido da Metropolitana $(R \$ 680,00)$. A região com menor ganho médio mensal é a Noroeste Fluminense (aproximadamente $\mathrm{R} \$ 470,00$ ).

Como avaliação das condições de vida e trabalho dos catadores, $27,8 \%$ dos profissionais afirma já terem sofrido algum tipo de acidente de trabalho na atividade de coleta e de separação dos materiais recicláveis. Na percepção de suas atividades frente à sociedade, 33,7\% se sente motivados a trabalhar e acreditam que a aceitabilidade por parte das pessoas com relação a suas atividades é positiva. Como principais motivos a se motivarem estão o fato de contribuírem para uma "cidade mais limpa" e de atuarem no "controle e despoluição dos rios".

É possível concluir que, embora a atividade de catador ainda seja uma atividade desprestigiada e mal classificada pela sociedade, é capaz de fazer com que os indivíduos voltem a se sentirem integrados a algo e a receber dinheiro que devolve a possibilidade de proverem seus lares.

Os resultados desta pesquisa podem ser utilizados para ampliar as discussões e reflexões em nível de políticas públicas diretamente ligadas a realizada dos catadores, capazes de fomentar modelos de gestão que contribuam para melhores condições de trabalho e de vida para estes atores atuantes como protagonistas no foco do tripé da gestão da sustentabilidade.

\section{Referências Bibliográficas}

ABREU, M. Do lixo à cidadania: estratégias para a ação. Brasília, 2001.

BAQUERO, M.; CREMONENSE, D. Capital social: teoria e prática. Ijuí: Unijuí, 2006.

BARRETO, B. M. V. B. Telejornalismo e Meio Ambiente nas Bordas da Mata Atlântica: carências e possibilidades em Itabuna, Bahia. Ilhéus-Bahia, Dissertação (mestrado em Desenvolvimento Regional e Meio Ambiente), PRODEMA/Universidade Estadual de Santa Cruz, 2004.

BOSI, A. P. A Organização capitalista do trabalho "informal" O caso dos catadores de recicláveis. Revista Brasileira de Ciências Sociais, 23(67), 101 - 191, 2008.

CAVALCANTE, V., DANTAS, M. Pesquisa qualitativa e pesquisa quantitativa. Ciências da Informação em Revista. Recife, 2006.

CAVALCANTI, C.(org.) Desenvolvimento e Natureza: estudo para uma sociedade sustentável. São Paulo: Cortez, 2003.

CEMPRE - Compromisso Empresarial para a Reciclagem. 2009. Relatório Geral. Disponível em $<$ http://www.cempre.org.br/serv_duvidas.php> Acesso: 05 novembro 2012.

CHIKARMANE, Poornima. Integrating Waste Pickers into Municipal Solid Waste Management in Pune, India. Políticas da WIEGO (Políticas Urbanas). No. 8. India, 2009.

FERREIRA, S. L., et al., Importância Ambiental do Trabalho dos Catadores de Materiais Recicláveis em Goiânia Goiás Brasil. In: XXX Congreso Interamericano de Ingeniería Sanitaria y Ambiental. Puntadel Este, Uruguay, 2006. Disponível em: $<$ http://www.bvsde.paho.org/bvsaidis/uruguay30/BR05415_Rabelo.pdf >. Acesso: 30 de agosto 2012.

FERREIRA, S.L. Os "catadores do lixo" na construção de uma nova cultura: a de separar o lixo e da consciência ambiental. Maringá (PR) n. 07. Revista Urutágua - Revista Acadêmica Multidiciplinar. 2005. 
FRAGA, A. B. O trabalho de quem vive do lixo: desigualdade social e suas dimensões simbólicas. Polêmica. Rio de Janeiro, 2012.

FRANCO, M. A. R. Planejamento ambiental para a cidade sustentável. São Paulo, Annablume, 2000 .

FUNDAÇÃO ALEXANDRE DE GUSMÃO - FUNAG. Instituto de Pesquisa de Relações Internacionais do Governo Federal. As 15 maiores economias do mundo (2015). Disponível em: http://www.funag.gov.br/ipri/index.php/equipe/47-informacoes/94-as-15-maiores-economias-domundo-em-pib-e-pib-ppp. Acesso em: 05 de maio de 2015.

GIL, Antônio C. Como elaborar projetos de pesquisa. 3. ed. São Paulo: Atlas, 1998.

IBGE, Instituto Brasileiro de Geografia e Estatística. Projeção da população do Brasil. 2010. Disponível em: <http://www.ibge.gov.br/home/presidencia/noticias/noticia_impressao.php?id_noticia=1272>. Acesso: 16 outubro 2012.

KICHENER. R. M., SAIDELLES. A. P. F., STUMM. E. P. M. Percepções e perfil dos catadores de materiais recicláveis de uma cidade do RS. Revista Brasileira de Gestão e Desenvolvimento Regional. v. 5, n. 3, p. 221-232, set-dez/2009, Taubaté, SP, Brasil.

LIMA, V. S.; CORDEIRO. J.S. Desafio do trabalho coletivo por cooperativa de catadores. Caso: COOPERVIVA - Cooperativa de Trabalho dos Catadores de Material Reaproveitável de Rio Claro / SP. In: III Colóquio Internacional de Epistemologia e Sociologia da Ciência da Administração, 2013, Florianópolis.

MAGERA, M. Os empresários do lixo: um paradoxo da modernidade. Campinas: Átomo. 2003.

MARTINS, A. C., A Busca de proteção ao trabalho dos catadores de lixo recicláveis: análise da experiência do Instituto lixo e Cidadania em Curitiba, PR. Dissertação (Mestrado) - Universidade Federal de Ponta Grossa, Ponta Grossa, 2007.

MARTINS, C. H. B. Trabalhadores na reciclagem do lixo: dinâmicas econômicas, sócio-ambientais e políticas na perspectiva do empreendedorismo. 2003. Tese de Doutorado (Sociologia). Programa de Pós-Graduação em Sociologia, Universidade Federal do Rio Grande do Sul, 2003, 211p.

MEDEIROS, L.F.R.; MACEDO, K.B. Catador de material reciclável: uma profissão para além da sobrevivência?.Psicologia \& Sociedade,18(2), 62-71, 2006.

MEDEIROS, L.F.R.; MACEDO, K.B. Profissão: catador de material reciclável, entre o viver e o sobreviver. Revista Brasileira de Gestão e Desenvolvimento Regional, 3(2), 72-94, 2007.

MEIRELleS, D. R. S., GOMES, L. C. M. A Busca da Cidadania A Cooperativa de Catadores de Materiais Recicláveis do Aterro Metropolitano de Jardim Gramacho, em Duque de Caxias - RJ. $2008 . \quad$ Disponível em: <http://www.abep.nepo.unicamp.br/encontro2008/docsPDF/ABEP2008_1139.pdf>. Acesso: 30 setembro 2012.

MIURA, P. C. O. Tornar-se catador: uma análise psicossocial. Dissertação (Mestrado) Pontifícia Universidade Católica de São Paulo, São Paulo, 2004.

NETO, A. L. G. C., et al., Consciência ambiental e os catadores de lixo do lixão da cidade do Carpina-Pe. Revista Eletrônica do Mestrado em Educação Ambiental, 19, 99-109, 2007. 
OLIVEIRA, Maria M. Como fazer pesquisa qualitativa. Recife: Ed. Bagaço, 2005.

OLIVEIRA, N.M.S; et.al. Estudo Gravimétrico de Resíduos Vítreos domésticos do Lixão de Campina Grande - PB. In: 51ํ Congresso Brasileiro de Cerâmica, 2007. Salvador - BA.

ORGANIZAÇÃO PARA A COOPERAÇÃO E DESENVOLVIMENTO ECONÔMICO (OCDE). Relatório Territorial Brasil 2013. 2013. Disponível em: http://oglobo.globo.com/economia/brasil-temsegunda-pior-distribuicao-de-renda-em-ranking-da-ocde-7887116. Acesso em: 05 de maio de 2015.

PORTO, M. F. S. JUNCÁ, D. C. M., GONÇALVES, R. S., FILHOTE, M. I. F. Lixo, trabalho e saúde: um estudo de caso com catadores em um aterro metropolitano no Rio de Janeiro, Brasil. Caderno Saúde Pública, 20(6)1503-1514, 2004.

ROSADO, R. M. Por uma cartografia do lixo seco de Porto Alegre/RS/Brasil: Catadores, complexidade e educação ambiental. In: V CongresoEuropeoCeisal de Latinoamericanistas, 2007, Bruxelas.

SANTOS, J. G.; FERREIRA, C. E. V.; RAMALHO, A. M. C.; MACEDO, N. M. M. N. A importância das cooperativas de reciclagem na gestão dos resíduos sólidos urbanos: um estudo em uma cooperativa de Campina Grande - PB. In: XIV Seminário em Administração, 2011, São Paulo.

SILVA, E. R.; YAMAMURA, F. Y.; AGUIAR, L. V.; MONTENEGRO, M.; ALUISIO, U. Avaliação das condições ambientais e de trabalho de uma cooperativa de catadores no Rio de Janeiro. In: $\mathrm{V}$ Congresso Nacional de Excelência em Gestão, Anais... 2009, Niterói.

TEIXEIRA, M., MALHEIROS, T. M.M. Cooperativas de catadores de lixo - um processo de inclusão social. Rio de Janeiro, 2010.

ZUCATTO, L. C.; ZEN, A. C.; BOLZAN, T. S. Cooperativa Popular de Catadores de Lixo Urbano e o Desenvolvimento Sustentável de Pequenos Municípios: Um Estudo de Caso da CALIXO. In: X Encontro Nacional de Gestão Empresarial e Meio Ambiente, 2008, Porto Alegre. 